\title{
Recrystallization Response during Thermo-Mechanical Processing of Alloy René 65 Billet
}

\author{
Ramesh S. Minisandram ${ }^{1}$, Laurence A. Jackman ${ }^{1}$, Jeffrey L. Russell ${ }^{1}$, \\ Michael L. Lasonde ${ }^{2}$, Joseph A. Heaney ${ }^{2}$, Andrew M. Powell ${ }^{2}$ \\ ${ }^{1}$ ATI Specialty Materials \\ 2020 Ashcraft Avenue, Monroe, NC 28110, USA \\ ${ }^{2}$ GE-Aviation \\ One Neumann Way, Cincinnati, OH 45215, USA
}

Keywords: Recrystallization, René 65, Superalloy, Nickel-base, Cast and Wrought

\begin{abstract}
The recrystallization behavior of René 65 billet was characterized using a combination of subscale compression samples and full-scale forgings. Two different billet conversion practices were utilized to develop a range of starting billet microstructures with respect to the percent unrecrystallized grains. These billets provided the sub-scale compression samples and input material for full-scale forgings. Processing parameters studied were strain and strain rate representing a wide range of forging processes. Strain distributions within the sub-scale compression samples were determined using deformation modeling. Microstructures after compression were mapped as a function of processing parameters. The effect of unrecrystallized grains on low cycle fatigue (LCF) was evaluated.
\end{abstract}

\section{Introduction}

René 65 is a new $\gamma^{\prime}$-strengthened Ni-base superalloy that was developed as a cost-effective alloy for higher temperatures in aerospace applications such as disks ${ }^{1,2}$. As is typical for such applications, emphasis is placed by industry on producing material with uniform grain structures which contain fewer and smaller unrecrystallized grains. This investigation is directed at establishing the effect of forging parameters on the recrystallization behavior of René 65 billet in response to typical forging parameters used during forging of disks. A matrix of sub-scale compression tests was used to generate this relationship. Full-scale pancakes were subsequently forged to assess the effect of unrecrystallized grains on low cycle fatigue (LCF). Test samples were obtained from 2 types of billet material. One billet contained a lower amount of unrecrystallized grains $(\sim 1 \%)$. Based on the billet heat number, this material was designated as ' $\mathrm{H}$ ' material. In order to assess the impact of unusually high volume fraction of unrecrystallized grains, a second billet was produced using non-standard experimental forging procedures that generated a higher volume fraction of unrecrystallized grains (3-5\%). This was designated as ' $\mathrm{X}$ ' material. Figure 1 illustrates the starting microstructure from each billet and demonstrates the inherent variability in the distribution of unrecrystallized grains. This is especially true of the ' $\mathrm{H}^{\prime}$ billet in which the unrecrystallized grains were much sparser. 

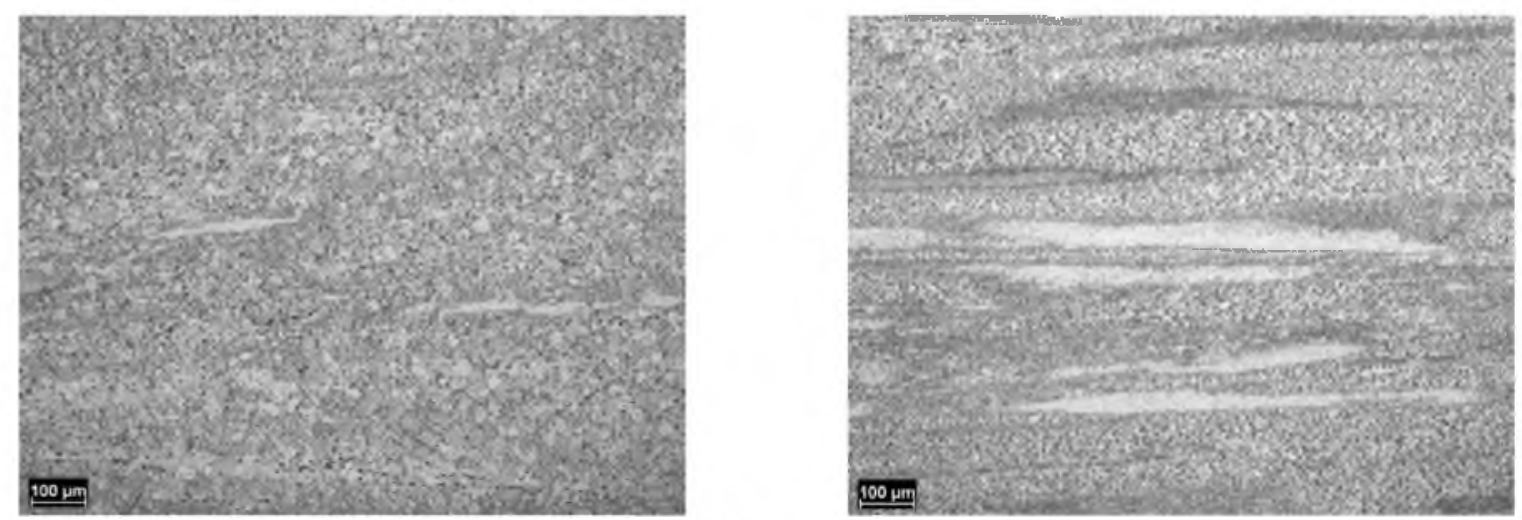

Figure 1. Starting microstructure in the ' $\mathrm{H}$ ' billet (left) and in the ' $\mathrm{X}$ ' billet (right).

\section{Subscale Compression Tests}

Sample preparation

At the outset, careful consideration was given to the optimum sample size needed for sub-scale compression testing; the samples needed to be large enough to include a sufficient number of unrecrystallized grains, but small enough to fit on the test equipment. After testing different size specimens ranging in diameter from $12.7 \mathrm{~mm}(0.5 \mathrm{in})$ to $38.1 \mathrm{~mm}(1.5 \mathrm{in})$ with aspect ratios between 1 and 2 , it was determined that the dimensions that worked best were $25.4 \mathrm{~mm}$ dia.(1in) $\mathrm{x} 38.1 \mathrm{~mm}$ (1.5in) length. Test samples of this size were machined using wire electric discharge machining from the interior of $254 \mathrm{~mm}$ (10in) diameter billet (Figure 2). The samples were machined from regions with a high density of unrecrystallized grains as determined by a macroplate taken adjacent to the mult for samples.

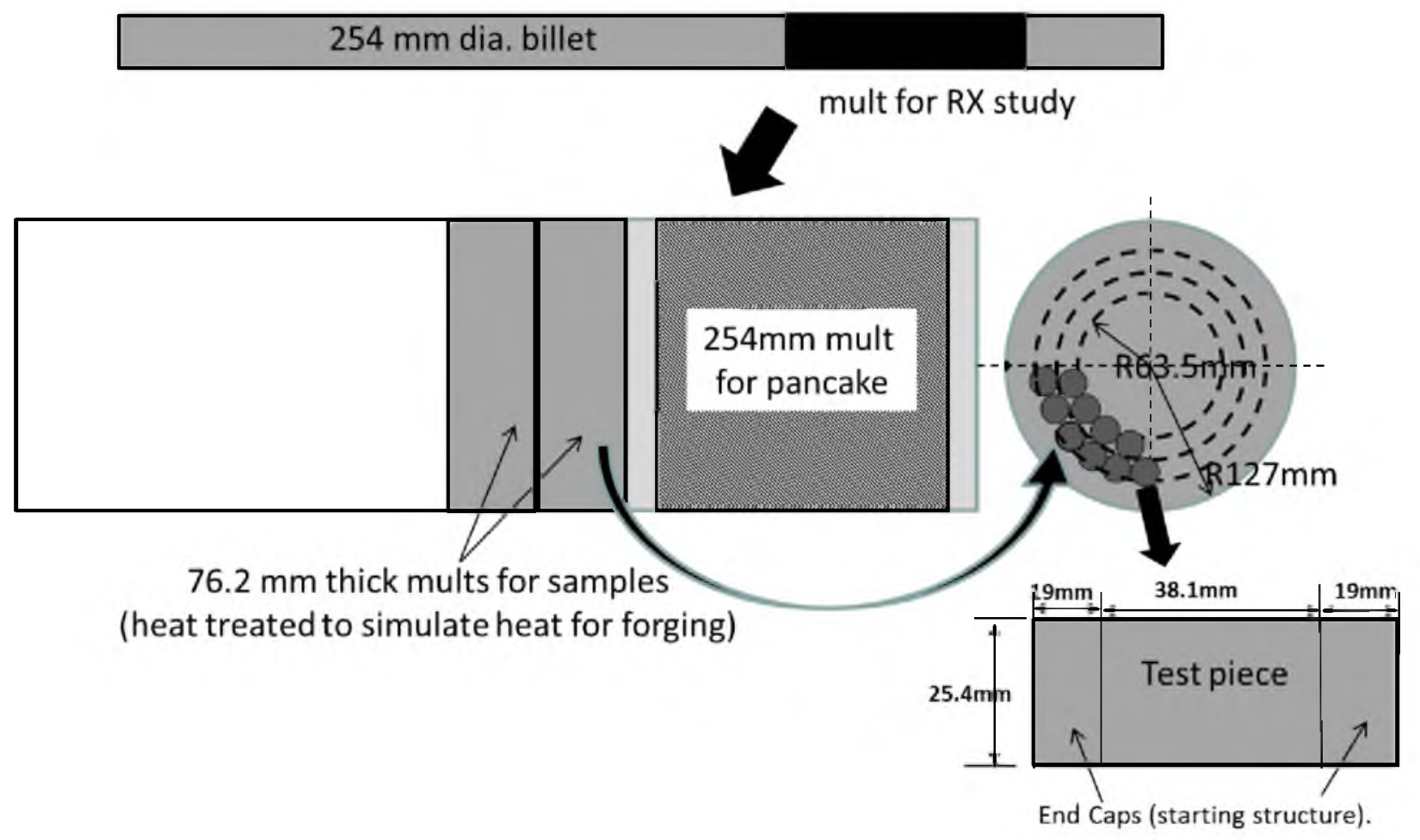

Figure 2. Cutting plan for sub-scale and pancake test specimens from $254 \mathrm{~mm}$ dia. billet. 


\section{$\underline{\text { Test Procedure }}$}

The $76.2 \mathrm{~mm}$ thick mults were heated at $1052^{\circ} \mathrm{C}\left(1925^{\circ} \mathrm{F}\right)$ for 5 hours to simulate the heating prior to forge. For each of " $\mathrm{H}$ " and "X" materials, a total of 15 sub-scale tests were conducted at the strains and strain rates shown in Table 1. The tests were performed at Wright State University, Dayton, Ohio, on a 220 kip hydraulic testing machine equipped with a controlled atmosphere furnace. TZM Dies and dry graphite spray lubricant were used. All tests were conducted from $1052^{\circ} \mathrm{C}\left(1925^{\circ} \mathrm{F}\right)$. The biggest challenge faced during the design of the forging practice was the tendency of samples to skew laterally, especially for low strain tests. Figure 3 shows a typical sample before and after forging
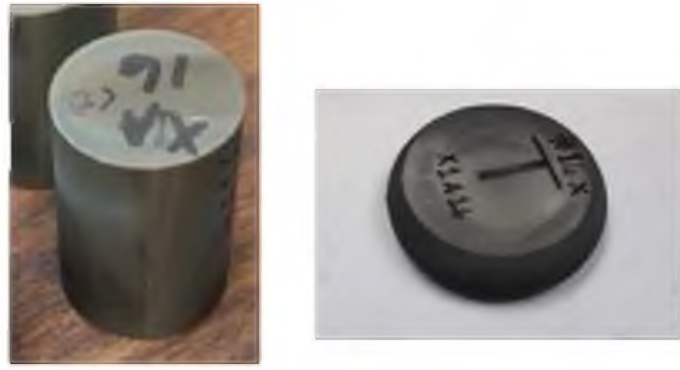

Figure 3. Specimen configuration in typical test before (left), after forging (right).

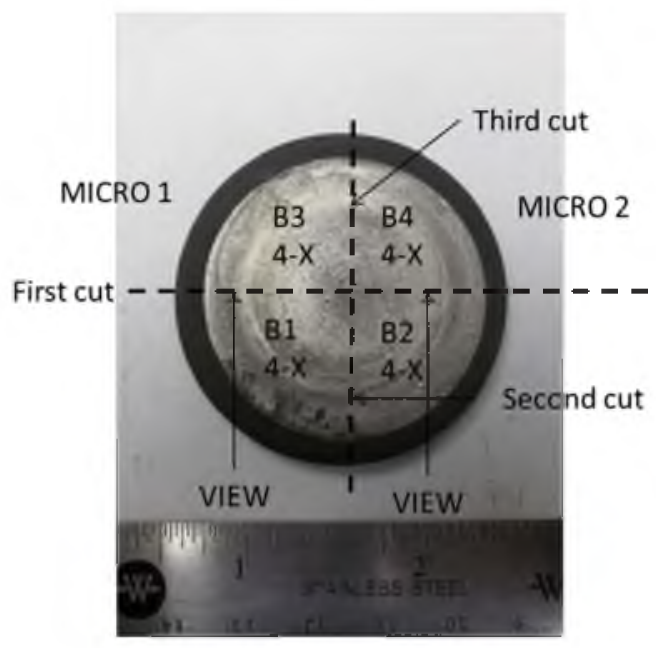

Figure 4. Cutting plan for forged specimens

Table 1. Sub-scale test matrix

\begin{tabular}{|c|c|c|c|}
\hline Test number & strain rate & $\begin{array}{c}\text { finish height } \\
(\mathrm{mm})\end{array}$ & $\begin{array}{c}\text { total } \\
\text { strain }\end{array}$ \\
\hline 1 & 0.001 & 25.4 & 0.4 \\
\hline 2 & 0.001 & 19.0 & 0.7 \\
\hline 3 & 0.001 & 12.7 & 1.1 \\
\hline 4 & 0.01 & 25.4 & 0.4 \\
\hline 5 & 0.01 & 19.0 & 0.7 \\
\hline 6 & 0.01 & 12.7 & 1.1 \\
\hline 7 & 0.1 & 25.4 & 0.4 \\
\hline 8 & 0.1 & 19.0 & 0.7 \\
\hline 9 & 0.1 & 12.7 & 1.1 \\
\hline 10 & 0.5 & 25.4 & 0.4 \\
\hline 11 & 0.5 & 19.0 & 0.7 \\
\hline 12 & 0.5 & 12.7 & 1.1 \\
\hline 13 & 1 & 25.4 & 0.4 \\
\hline 14 & 1 & 19.0 & 0.7 \\
\hline 15 & 1 & 12.7 & 1.1 \\
\hline
\end{tabular}

During sample processing, care was taken to maintain the location and orientation of each sample in the original billet mult from which it was machined. This ensured consistency in the subsequent characterization and measurements. Each sample was cut to view the longitudinal surface as shown in Figure 4. The micros were all heat-treated at $1066^{\circ} \mathrm{C}\left(1950^{\circ} \mathrm{F}\right)$ for one hour prior to evaluation. The faces of the quarters were polished and etched using a modified Kallings etch.

\section{Characterization \& Measurement}

- Using automated techniques, a stitched composite optical image of the entire quarter section at $25 \mathrm{X}$ was obtained (Figure $5 \mathrm{a}$ ) 
- Using thresholding, the unrecrystallized grains in each cross-section were highlighted (Figure 5b)
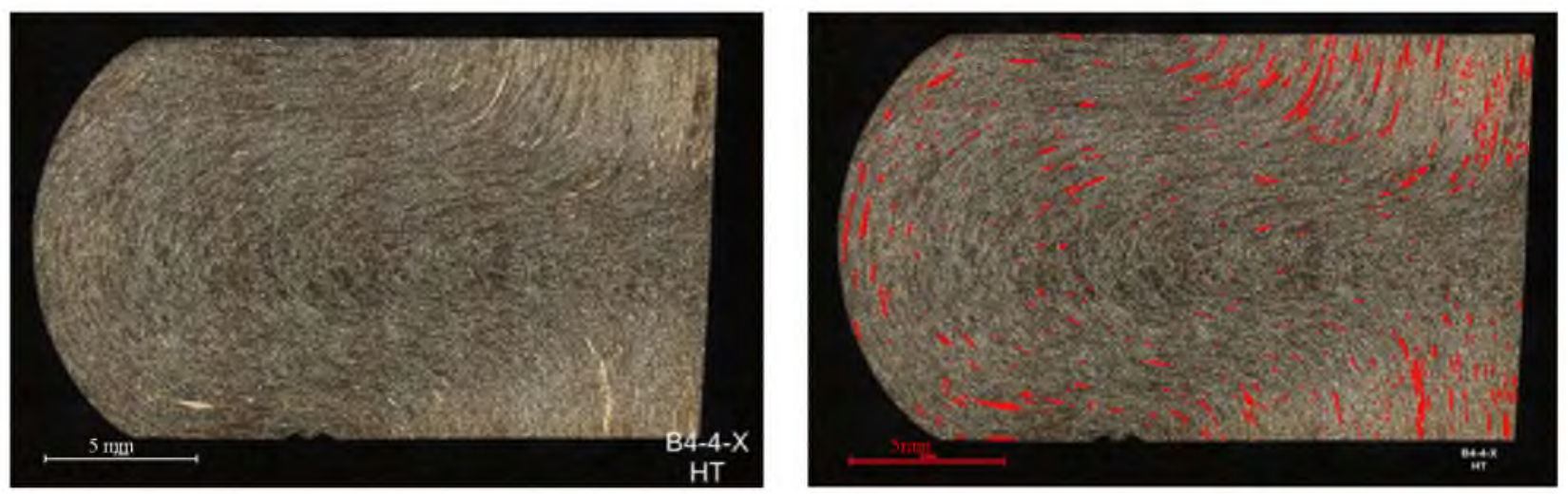

Figure 5. (a) Typical stitched image (left); (b) after thresholding.

- DEFORM-2D ${ }^{\mathrm{TM}}$ finite element simulation was used to get a strain distribution and establish strain zones within the cross-section. This is shown in Appendix I.

- Despite all efforts to minimize skewing during testing, several of the test samples showed top-versus-bottom asymmetry. In order to compensate for this skewness (and also some top-to-bottom variability inherent in the starting structure), the strain zones included for measurement of the percent and size of unrecrystallized grains were limited to the central zone (roughly middle third) of all samples. This is illustrated in Appendix I.

- The relevant central zone strain map was superimposed on the thresholded image (Figure 6). Table 2 shows the strains and corresponding zones in the forged specimens.

Table 2. Definition of Strain Zones

\begin{tabular}{|l|c|c|c|c|}
\hline \multirow{2}{*}{$\begin{array}{l}\text { Strain } \\
\text { Range }\end{array}$} & $\begin{array}{c}\text { Mid-point } \\
\text { of range }\end{array}$ & \multirow{2}{*}{$12.7 \mathrm{~mm}$ samples } & $\begin{array}{c}19.0 \mathrm{~mm} \\
\text { samples }\end{array}$ & $\begin{array}{c}25.4 \mathrm{~mm} \\
\text { samples }\end{array}$ \\
\hline $0.0-0.36$ & $\mathrm{~N} / \mathrm{A}$ & \multirow{2}{*}{$\begin{array}{c}\text { Zone 1: die-lock } \\
\text { (starting structure) }\end{array}$} & $\begin{array}{c}\text { Zone 1: die-lock } \\
\text { (starting structure) }\end{array}$ \\
\cline { 1 - 1 } & 0.54 & \multicolumn{3}{|c|}{ Zone 1B } \\
\hline $0.36-0.72$ & \multicolumn{3}{|c|}{ Zone 2 3} & N/A \\
\hline $1.08-1.08$ & 0.90 & \multicolumn{2}{|c|}{ N/A } \\
\hline $1.44-1.80$ & 1.26 & Zone 4 & N/A \\
\hline $1.80-2.16$ & 1.62 & Zone 5 & \multicolumn{3}{|c|}{} \\
\hline
\end{tabular}
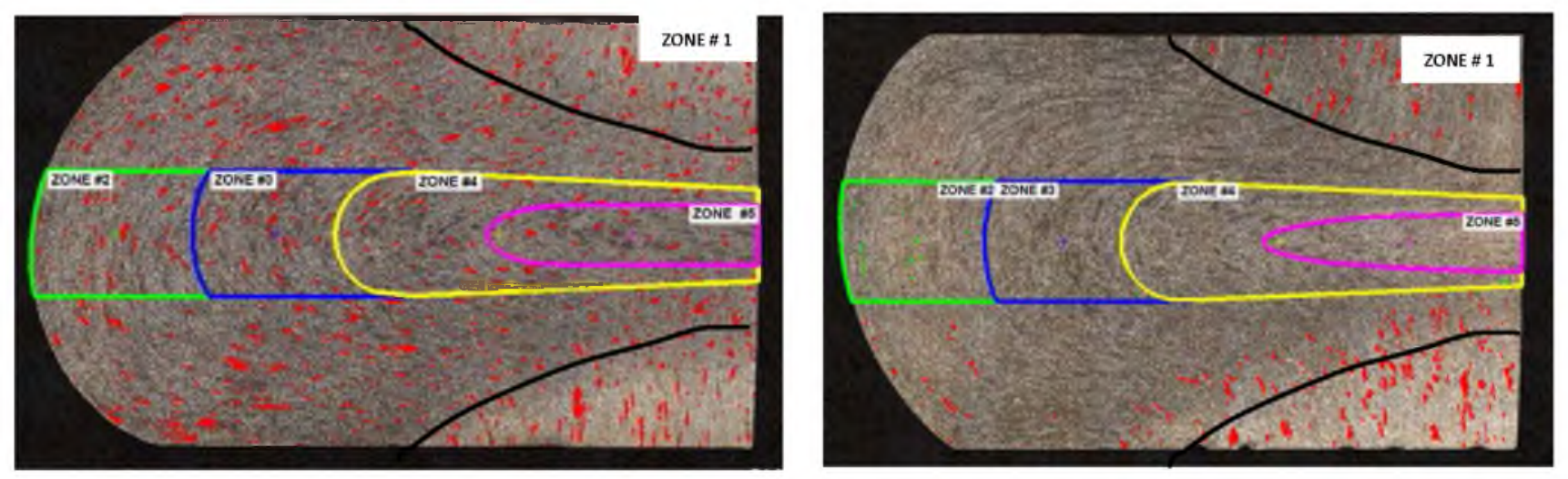

Figure 6. Thresholded images with superimposed central strain zones. (a) forged at $0.001 \mathrm{~s}^{-1}$ (left); (b) forged at $1.0 \mathrm{~s}^{-1}$. Both samples are from $\mathrm{X}$ heat forged to $12.7 \mathrm{~mm}(0.5 \mathrm{in})$ height. 
- The die-lock regions in each sample were used to estimate the fraction unrecrystallized in the forging stock.

- For each strain zone, including the die-lock region, the size and distribution of unrecrystallized grains was measured and the percent unrecrystallized calculated (Figure 7). Only unrecrystallized grains equal to or greater in area than ASTM 5 were counted.

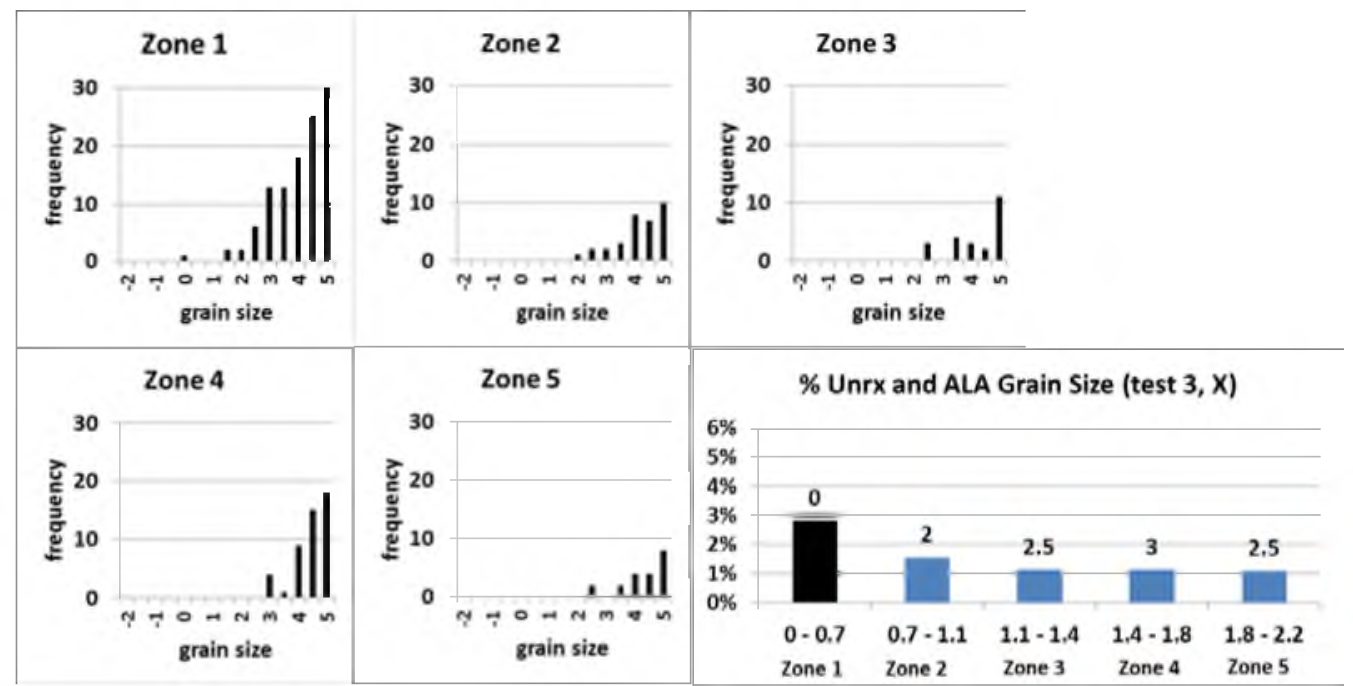

Figure 7. Distribution of unrecrystallized grains in each strain zone shown on the left of Figure 6; the sample was from the $X$ heat and compressed at $0.001 \mathrm{~s}^{-1}$ strain rate to $12.7 \mathrm{~mm}(0.5 \mathrm{in})$ finish height. The bottom right graph above shows the combined distribution for this sample

- In order to minimize effects of the inherent non-uniform distribution of unrecrystallized grains in the billet material, the average of all starting \% unrecrystallized values for samples from heat $\mathrm{H}$ was used to represent the starting \% unrecrystallized for all $\mathrm{H}$ samples; starting \% unrecrystallized values were taken from dielock regions. Similarly, the average of all measured starting \% unrecrystallized values for samples from heat $\mathrm{X}$ was used for all $\mathrm{X}$ samples. For each sample from heat $\mathrm{H}$ and from heat $\mathrm{X}$, the measured $\%$ unrecrystallized in each strain zone $(\mathrm{Zi})$ was normalized as follows:

Normalized $\% \mathrm{UNRX}$ for $\mathrm{Zi}=\left\{\frac{\text { avg. starting } \% \mathrm{UNRX} \text { for Heat }}{\text { starting } \% \mathrm{UNRX} \text { for sample }}\right\}$ (raw \%UNRX for Zi)

Figure 8 shows typical results before and after the normalization procedure for heat $\mathrm{X}$. The numbers above the bars for the initial structures refer to the As Large As unrecrystallized grain size (ALA). Values of ALA grains for the other strain regions are in Appendix II. The ALA grains have not been normalized. Note that the results in Figure 8 are for all samples forged to $12.7 \mathrm{~mm}(0.5 \mathrm{in})$ finish size only. A similar normalization procedure was applied to the samples forged to $19 \mathrm{~mm}(0.75 \mathrm{in})$ and 25.4 $\mathrm{mm}$ ( 1 in) finish heights 


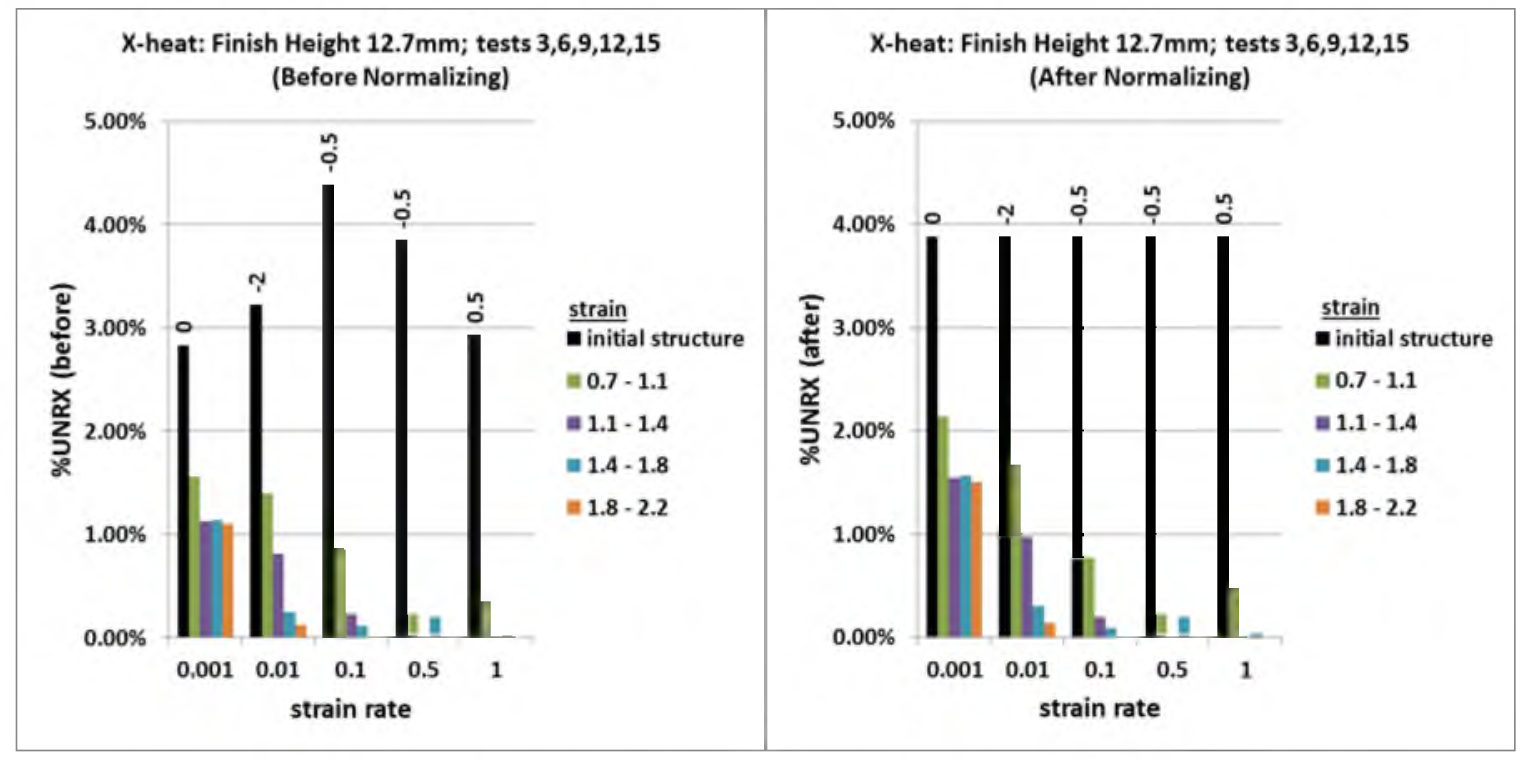

Figure 8. \%UNRX results for all $12.7 \mathrm{~mm}$ heat $\mathrm{X}$ specimens (a) before normalization (left) and (b) after normalization (right).

- Finally, for each given heat and strain rate value, the average of the normalized percent unrecrystallized in all similar valued strain zones for all samples $(12.7 \mathrm{~mm}, 19 \mathrm{~mm}$, $25.4 \mathrm{~mm}$ finish height) was calculated to represent the combined effect of strain and strain rate on the recrystallization behavior of the heat.

\section{$\underline{\text { Results }}$}

The final values after normalization and averaging over all similar valued strain zones across all samples (final heights $12.7 \mathrm{~mm}, 19.0 \mathrm{~mm}, 25.4 \mathrm{~mm}$ ) are shown in Figure 9 (a) \& (b) for heats X \& $\mathrm{H}$ respectively. Appendix II has the numerical values along with the sizes of ALA grains.

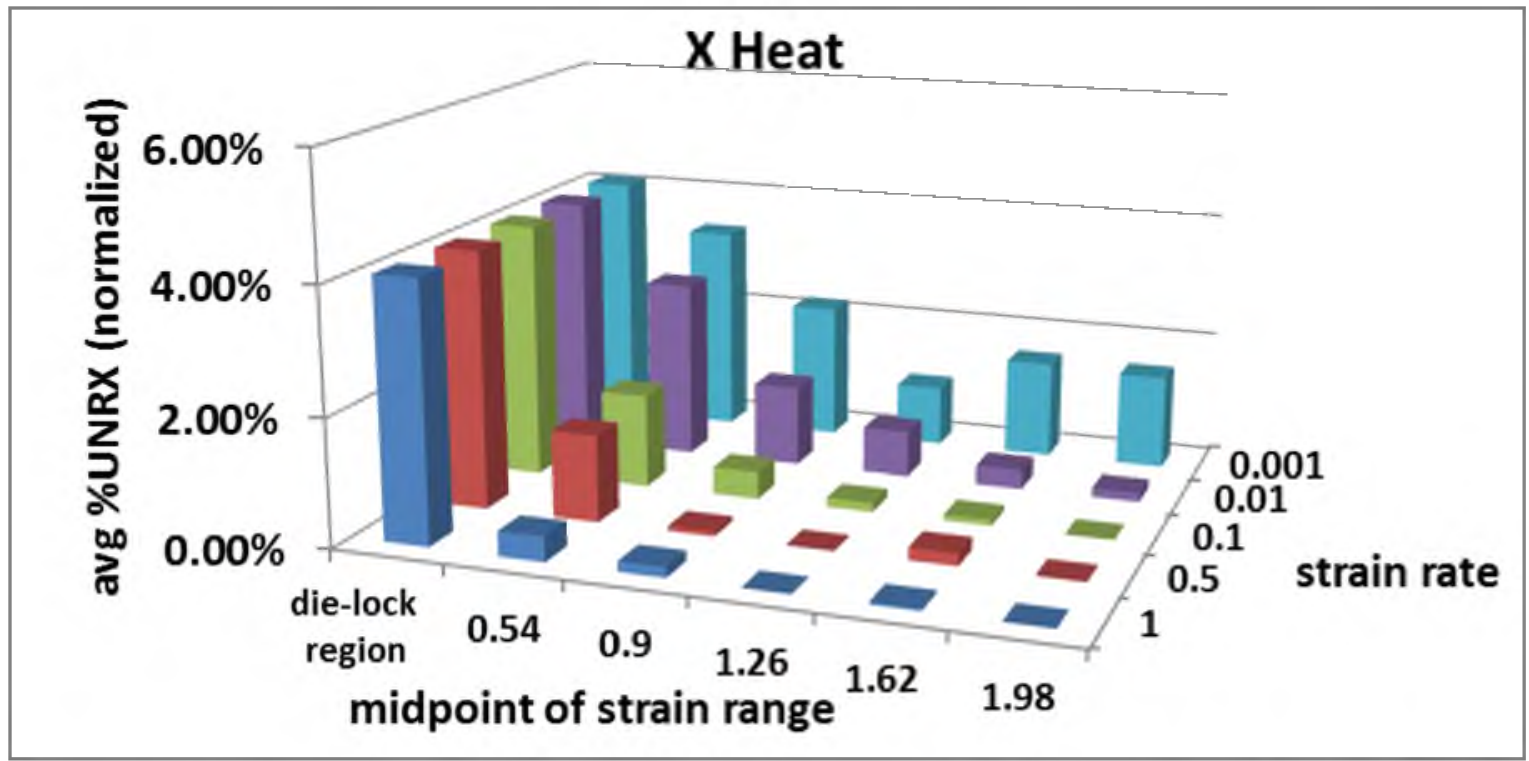

Figure 9 (a). Summary plot showing results of the analysis of all sub-scale testing described in Table 1 (for X heat). Note that scale for \%UNRX is different than that in Figure 9 (b). 


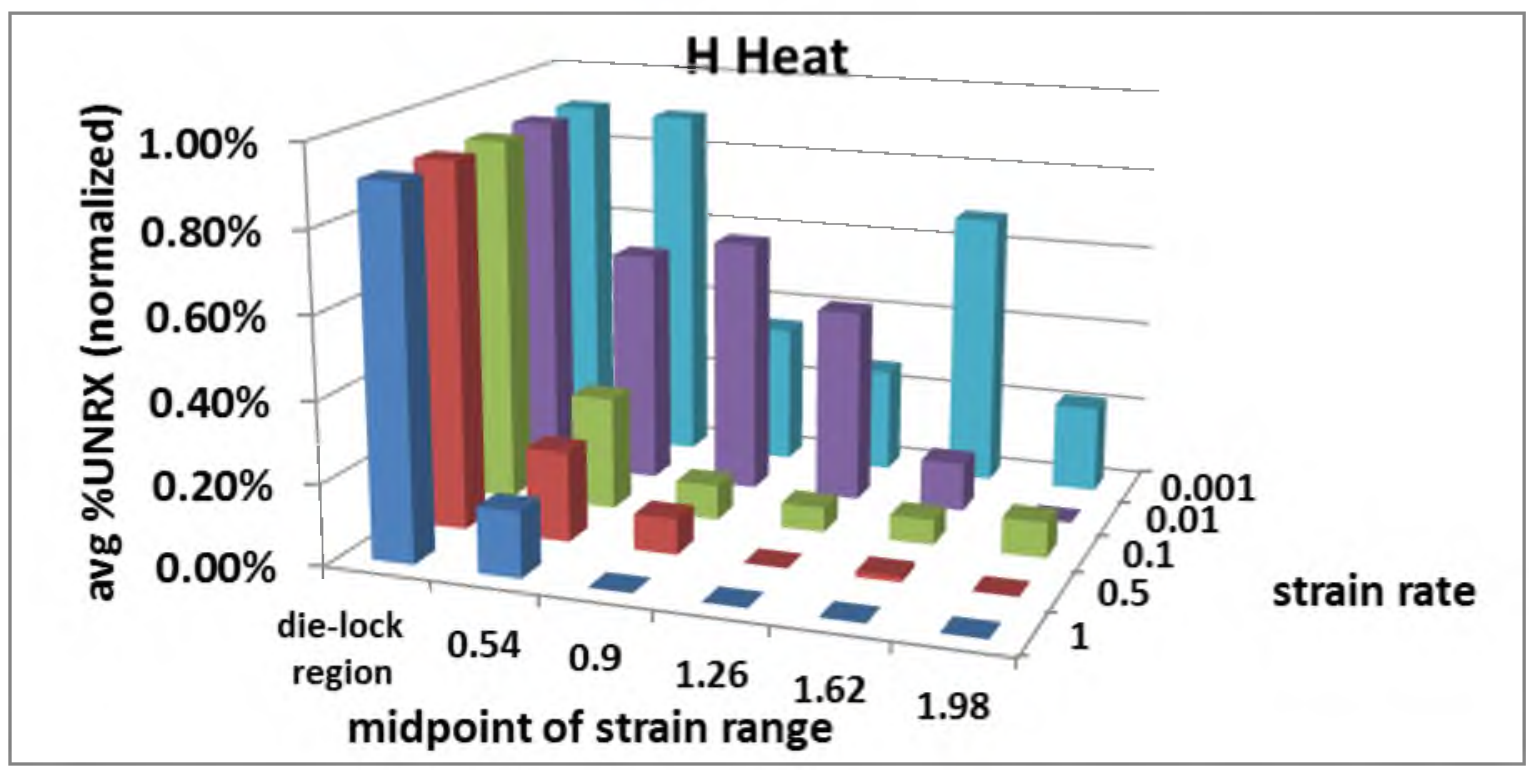

Figure 9 (b). Summary plot showing results of the analysis of all sub-scale testing described in

Table 1 (for $\mathrm{H}$ heat). Note that scale for \%UNRX is different than that in Figure 9 (a).

Figure 9 highlights the following:

- Both strain and strain rate are major factors in reducing the amount and size of unrecrystallized grains.

- For all combinations of strain and strain rate, a reduction in ALA grain size and percent unrecrystallized grains relative to the starting structure was observed.

- These reductions were more pronounced with increasing strain and strain rate.

- The above apply to both the $\mathrm{H}$ heat (sparser initial unrecrystallized grains) and the $\mathrm{X}$ heat (higher amounts of unrecrystallized grains).

- The effects of increasing strain and/or strain rate in reducing unrecrystallized structure are less consistent for the lowest strain rates (0.001). This is attributed to the inherent variability in distribution of unrecrystallized grains in the starting structure.

One effect of increasing the amount of deformation (higher strain) is the resulting temperature rise (deformation heating). If the rate of deformation is also increased (higher strain rates), there is less time for this heat to dissipate. Figure 10 shows the temperature rise at various strain rates predicted by DEFORM-2D ${ }^{\mathrm{TM}}$ for compression of the samples used in this study to $12.7 \mathrm{~mm}(0.5 \mathrm{in})$ finish height. It shows that for strain rates higher than $0.1 \mathrm{~s}^{-1}$, there is significant deformation heating in the test specimens. This rise in temperature may be a factor in reducing the unrecrystallized structure in the samples with

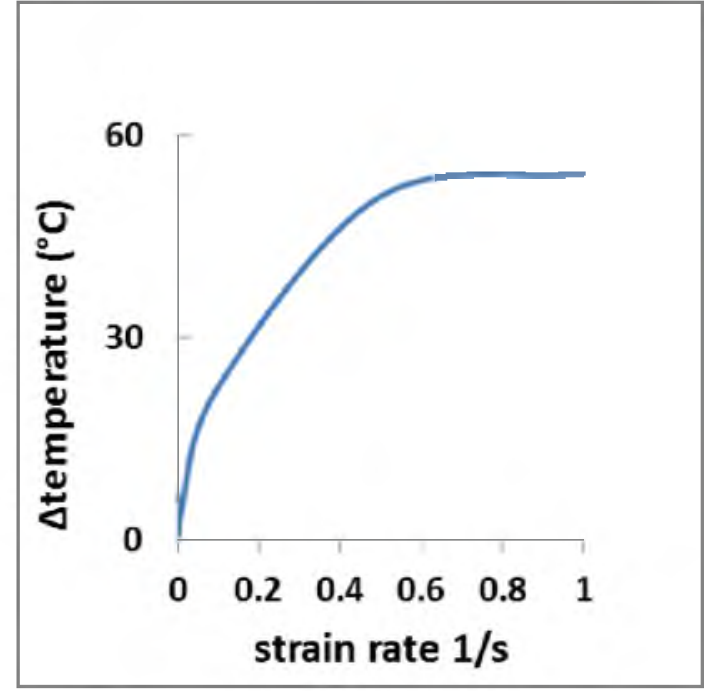

Figure 10. Predicted Temperature Rise from Deformation Heating for Compression of $25.4 \mathrm{~mm}$ dia. specimen from $38.1 \mathrm{~mm}$ to $12.7 \mathrm{~mm}$. 
higher strain/strain rate combinations. Grain coarsening was not observed in any of these samples, because of the small size of samples and the high cooling rates after deformation.

\section{Full Scale Forgings}

A major objective for forging full-scale pancakes was to provide material with unrecrystallized grains for low cycle fatigue (LCF) testing. The pancakes were forged using strain rates that were in the lower end of the strain rate range $\left(<0.2 \mathrm{~s}^{-1}\right)$ used for the sub-scale testing. Forging mults were removed from billet locations adjacent to the material utilized for sub-scale test specimens. The $254 \mathrm{~mm}$ (10in) dia. mults were hot die forged to a pancake configuration measuring approximately $457 \mathrm{~mm}$ dia. $\times 76 \mathrm{~mm}$ thick (18in dia. $x$ 3in thick). Subsequent to forging, the pancakes were solution heat treated at $1066^{\circ} \mathrm{C}\left(1950^{\circ} \mathrm{F}\right)$, oil quenched, and aged at $760^{\circ} \mathrm{C}$ $\left(1400^{\circ} \mathrm{F}\right)$. High sensitivity, multizone ultrasonic testing was performed to identify any areas of coarse grain for LCF testing. Coarse unrecrystallized grains were observed in some of the zones evaluated. The coarse grain region identified in Zone 2 (Z2) is illustrated in Figure 11 and was selected for additional evaluation. Zone 1 (Z1) in Figure 11 is shown for comparison.

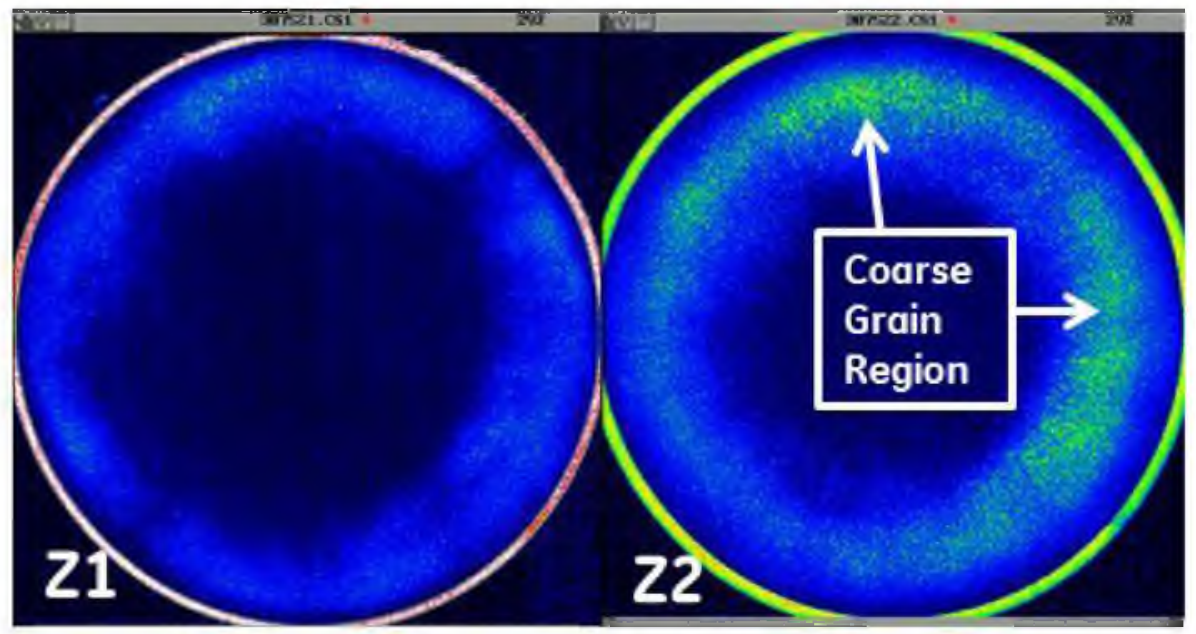

Figure 11. Ultrasonic Test Results Showing a Coarse Grain Region in Zone 2

Axial-axial strain control LCF specimens were machined from the coarser grain region identified above. Post-analysis of the test specimens showed the distribution of coarse unrecrystallized grains presented in Figure 12

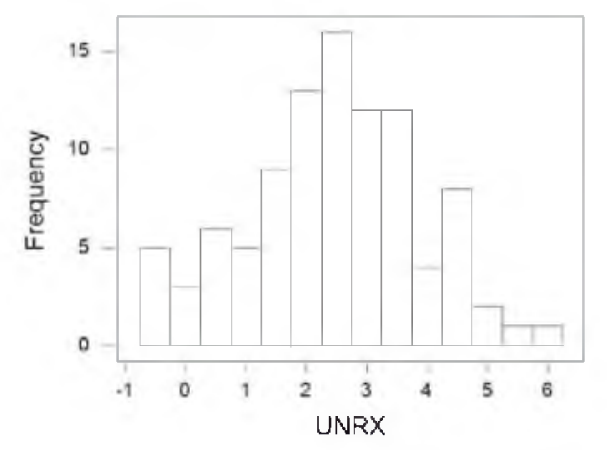

Figure 12. Distribution of Unrecrystallized Grains in ASTM Grain Sizes 
Fractographic analysis of bars tested at both $400^{\circ} \mathrm{C}\left(750^{\circ} \mathrm{F}\right)$ and $649^{\circ} \mathrm{C}\left(1200^{\circ} \mathrm{F}\right)$ revealed that none of the failures originated at an unrecrystallized grain. The distribution of lives for material tested representing the coarsest unrecrystallized grains observed was consistent with the behavior of typical production material.

\section{Conclusions}

Sub-scale compression tests were used to study the effect of forge process conditions on the recrystallization response of René 65 billet. A complicating factor in this study was the inherent variability in the distribution of unrecrystallized grains in the billet structure. The process parameters evaluated were strain and strain rate. Two billets containing significantly different amounts of unrecrystallized grains were utilized as input material. For both materials, the size and number of unrecrystallized grains decreased with increasing strain and with increasing strain rate. Deformation heating at the higher strains and strain rates may play a role in this increased effectiveness.

Full scale pancake forgings were made from mults taken from the same billets adjacent to the location of the subscale samples. The resulting pancakes had regions of coarse unrecrystallized grains found by high sensitivity, multi-zone ultrasonic testing. LCF specimens from these coarse grain locations were tested. Fractographic analysis of the tested bars revealed that none of the failures originated at an unrecrystallized grain. Also, the distribution of lives for material tested representing the coarsest unrecrystallized grains observed was consistent with the behavior of typical production material. However, there are other benefits to be gained from reducing the amounts and sizes of unrecrystallized grains; an example is improved ultrasonic inspectability.

\section{Acknowledgements}

The authors would like to acknowledge the valuable metallographic assistance provided by $\mathrm{Mr}$. Shawn Rushing and the technical support during compression testing provided by Dr. Raghu Srinivasan of Wright State University.

\section{References}

(1) J.A. Heaney, M.L. Lasonde, A.M. Powell, B.J. Bond, C.M. O’Brien, Development of a New Cast and Wrought Alloy (Rene' 65) for High Temperature Disk Applications, Superalloys 718, 625,706 and Various Derivatives, ed. Banik, et al, TMS, 2014.

(2) B.J. Bond, C.M. O’Brien, J.L. Russell, J.A. Heaney, M.L. Lasonde, René 65 Billet Material for Forged Turbine Components, Superalloys 718, 625,706 and Various Derivatives, ed. Banik, et al, TMS, 2014. 


\section{Appendix I}

\section{Definition of Strain Zones}

Strain maps generated using DEFORM-2D ${ }^{\mathrm{TM}}$ were adapted to define the strain zones used for measurement of the percent unrecrystallized and size in the compressed samples, as shown below.

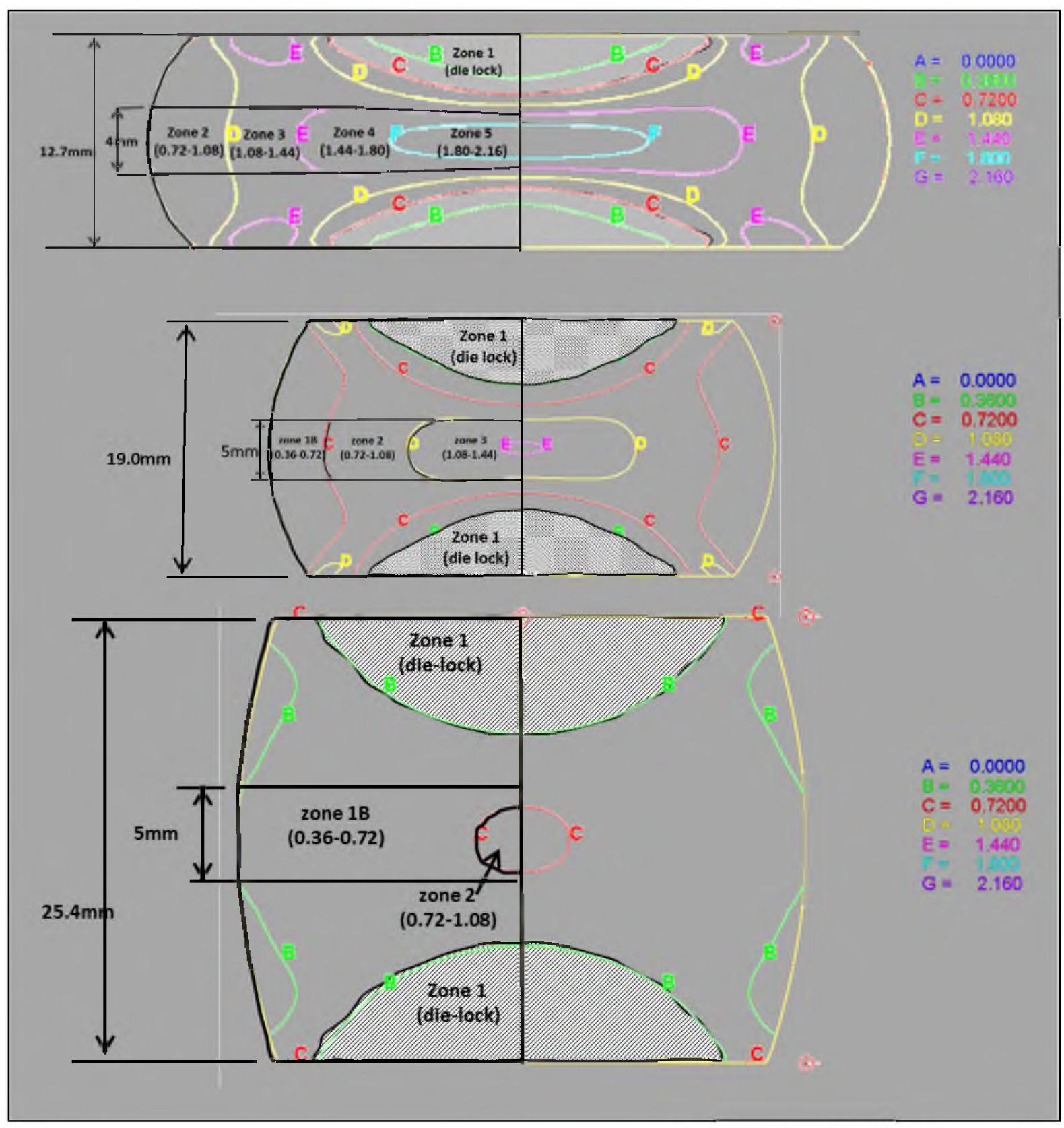




\section{Appendix II \\ Summary Results of Grain Size}

For each given heat and strain rate value, the \%UNRX numbers below represent the average of the normalized percent unrecrystallized in all similar valued strain zones for all samples (12.7mm, 19mm, 25.4mm finish height).

H heat

\begin{tabular}{|c|c|c|c|c|c|c|c|c|c|c|}
\hline $\begin{array}{l}\text { Strain } \\
\text { rate-> }\end{array}$ & \multicolumn{4}{|c|}{$\mathbf{0 . 0 0 1}$} & \multicolumn{2}{l|}{$\mathbf{0 . 0 1}$} & \multicolumn{2}{l|}{$\mathbf{0 . 1}$} & & \multicolumn{2}{l|}{} \\
\hline Strain & \%UNRX & ALA & \%UNRX & ALA & \%UNRX & ALA & \%UNRX & ALA & \%UNRX & ALA \\
\hline starting & $\mathbf{0 . 9 1 \%}$ & $\mathbf{1}$ & $\mathbf{0 . 9 1 \%}$ & $\mathbf{0 . 5}$ & $\mathbf{0 . 9 1 \%}$ & $\mathbf{0 . 5}$ & $\mathbf{0 . 9 1 \%}$ & $\mathbf{0 . 5}$ & $\mathbf{0 . 9 1 \%}$ & $\mathbf{0 . 5}$ \\
\hline 0.54 & $0.90 \%$ & 1 & $0.58 \%$ & 1 & $0.28 \%$ & 1.5 & $0.22 \%$ & 1.5 & $0.16 \%$ & 2 \\
\hline 0.9 & $0.35 \%$ & 2 & $0.63 \%$ & 1.5 & $0.09 \%$ & 2.5 & $0.09 \%$ & 2.5 & $0.00 \%$ & - \\
\hline 1.26 & $0.26 \%$ & 3 & $0.48 \%$ & 2.5 & $0.06 \%$ & 3.5 & $0.00 \%$ & - & $0.00 \%$ & - \\
\hline 1.62 & $0.68 \%$ & 4 & $0.12 \%$ & 3 & $0.06 \%$ & 4 & $0.01 \%$ & 4.5 & $0.00 \%$ & - \\
\hline 1.98 & $0.22 \%$ & 4 & $0.00 \%$ & - & $0.09 \%$ & 3 & $0.00 \%$ & - & $0.00 \%$ & - \\
\hline
\end{tabular}

$\underline{X \text { heat }}$

\begin{tabular}{|c|c|c|c|c|c|c|c|c|c|c|}
\hline $\begin{array}{l}\text { Strain } \\
\text { rate-> }\end{array}$ & \multicolumn{3}{|c|}{0.001} & \multicolumn{2}{c|}{0.01} & \multicolumn{2}{c|}{0.5} & \multicolumn{2}{c|}{1} \\
\hline Strain & \%UNRX & ALA & \%UNRX & ALA & \%UNRX & ALA & \%UNRX & ALA & \%UNRX & ALA \\
\hline starting & $\mathbf{4 . 0 9} \%$ & $-\mathbf{1}$ & $\mathbf{4 . 0 9 \%}$ & $\mathbf{- 2}$ & $\mathbf{4 . 0 9 \%}$ & $\mathbf{- 2}$ & $\mathbf{4 . 0 9 \%}$ & $-\mathbf{0 . 5}$ & $\mathbf{4 . 0 9 \%}$ & $-\mathbf{0 . 5}$ \\
\hline 0.54 & $3.35 \%$ & -1 & $2.85 \%$ & -0.5 & $1.48 \%$ & 0 & $1.37 \%$ & 0 & $0.39 \%$ & 2.5 \\
\hline 0.9 & $2.18 \%$ & 1 & $1.29 \%$ & 2 & $0.43 \%$ & 2 & $0.08 \%$ & 2 & $0.16 \%$ & 3 \\
\hline 1.26 & $0.97 \%$ & 2.5 & $0.74 \%$ & 0.5 & $0.15 \%$ & 3 & $0.00 \%$ & - & $0.00 \%$ & - \\
\hline 1.62 & $1.56 \%$ & 3 & $0.30 \%$ & 4.5 & $0.09 \%$ & 3 & $0.20 \%$ & 2 & $0.04 \%$ & 5 \\
\hline 1.98 & $1.51 \%$ & 2.5 & $0.14 \%$ & 4 & $0.00 \%$ & - & $0.00 \%$ & - & $0.00 \%$ & - \\
\hline
\end{tabular}

